\title{
Story, dialogue and caring about what matters to people: progress towards evidence enriched policy and practice
}

"People think that stories are shaped by people. In-fact it is the other way around" (Pratchett 2013, p12)

\begin{abstract}
Evidence-based practice in social care and health is widely promoted. Making it a reality remains challenging, largely because practitioners generally see practice-based knowledge as more relevant than empirical research. A further challenge regarding the creative, contextual use of research and other evidence including lived experience and practice-based knowledge is that practitioners, especially in frontline care services, are often seen not as innovators, but recipients of rules and guidelines or followers of pre-determined plans. Likewise, older people are not generally recognised as co-creators of knowledge, learning and development but as passive recipients of care, or objects of research.
\end{abstract}

This paper outlines a participatory action research project which brought together researchers; social care and health practitioners; managers; older people and carers in 6 sites across Wales and Scotland. Working collaboratively, and using a dialogic storytelling approach, they explored and addressed 7 already published research-based 'Challenges' regarding what matters most to older people with high-support needs. Taking a participatory, caring and emergent approach, participants discovered and addressed five elements required in developing evidence-enriched practice; the creation of supportive and relationship-centred research and practice environments; the valuing of diverse types of evidence; the use of engaging narratives to capture and share evidence; the use of dialogue-based approaches to learning and development; and the recognition and resolution of systemic barriers to development. Although existing literature covers each element, this project was novel in collectively exploring and addressing all five elements together, and in its use of multiple forms of story, which engaged hearts and minds.

\section{Key words:}

Evidence, storytelling, dialogue, knowledge exchange

\section{Background}

Within the context of health and social care services, this article explores an innovative approach to navigating the perspectives of diverse groups of participants and disparate, and at times conflicting types of knowledge (here collectively termed as evidence), in seeking to implement research informed change in organisations. The overall approach was a participatory research project, involving older people; carers; diverse social care and health practitioners; managers and researchers. Here we consider how participants collectively gathered, shared and responded to diverse types of knowledge, not all of which agreed with each other. Going beyond linear understandings of research implementation, we sought to progress an inclusive, dialogic and emergent approach to learning and development. We were particularly interested in the potential role of storytelling in seeking to negotiate (Strauss 1978) complex change in organisations.

The use of evidence in health and social care services is widely promoted. Making it a reality remains challenging (Huxley 2009, Greenhalgh et al 2014, Ghate and Hood 2019, Locock and Boaz 
2019). If research is to have impact in the real world, we must expand our understanding of what constitutes evidence beyond research knowledge and how it can be used (Gerrish et al 2011, Hall and Tandon 2017, Beresford 2018, Wieringa et al 2018, Metz et al 2019). For example, Gerrish et al (2011) distinguish four components of evidence: research knowledge; including research-based policy documents; practitioner knowledge and experience; organisational knowledge and the lived experience and voice of service users and carers. Challenges arises when these diverse types of knowledge conflict, leading to the question 'what counts as knowledge and whose knowledge counts?' (Hodgkin and Canvin 2005). Hall and Tandon use the provocative term 'epistemicide' (De Sousa Santos 2007), to describe when one type of knowledge dismisses another and suggest that "what is generally understood as knowledge in the universities of our world represents a very small proportion of the global treasury of knowledge" (Hall and Tandon 2019, p 7).

Knowledge exchange has emerged in response to growing understanding that successful uptake of research knowledge requires interaction between researchers, decision makers, and other stakeholders (Lavis et al 2003). Whilst respectful of practitioners, it supports critical reflection and can be effective in challenging discriminatory social and cultural norms and 'group speak' (Littleton and Mercer 2013, Green 2016). The concept of exchange certainly opens up possibilities for moving beyond the type of evidence-based 'guidelines' issued to practitioners, towards 'mindlines'. These have been described as "guidelines-in-the-head, in which evidence from a wide range of sources has been melded with tacit knowledge through experience and continual learning to become internalised as a... guide to practising in varied contexts" (Author 2 and author 3 2016). They are based on a more fluid, transformational and relational view of evidence which accommodates context and acknowledges multiple types of knowledge as collective evidence (Author 2 and author 3 2004).

In the context of health and social care services the value of kindness and caring dialogue can easily be overlooked (Ballatt and Campling 2011, Unwin 2018), despite the fact that dialogue within organisations is necessary for the wellbeing of employees and in turn, to enable diverse colleagues to work towards better outcomes for the people they support:

"...the quality of reach of dialogue within organisations needs to be sufficient for practitioners to feel valued and listened to, and for different parts of the organisation, including frontline practice and information people, to understand each other's contributions to achieving outcomes" (Author 4 and Author X 2016, p5).

Beyond the need for dialogue in general, researchers and others who wish to use research knowledge in practice must seek to open dialogue with those they wish to engage in evidenceinformed policy and practice development. Lessons from social pedagogy caution against imposing knowledge on unwilling recipients (Horton and Freire 1990, Riebe et al 2016) and lessons from philosophy remind us that "truths are accepted as facts only when they become interesting" (Wierenga et al 2018, p 932). Dialogue is required both to open up space for exchanging knowledge and experience and importantly, to build the relationships and interest, which are necessary for engagement of all participants in change. The relational aspect of dialogue is often understated, but is central to overcoming fears, assumptions and defensiveness which can block new learning (Author 1 et al 2009, Escobar 2012) and the transformation of policy and practice. Dialogue is not just about talking; it is a caring, values-based activity (Booth and Ainslow 2016).

In considering the use of evidence in health and social care services for older people with high support needs (the topic of this article), there are two additional challenges, that need to be acknowledged and addressed. The first challenge is to overcome the historical discourse regarding older people, which highlights deficit, loss and dependency (Bowers et al 2013), particularly for 
people living with dementia (Bartlett and O'Connor, 2007). This shapes the culture of care and support services, within which older people are often seen as passive recipients of care (Cahn 2000, Nolan et al 2006) rather than active participants in knowledge exchange and care transformation. As a result, the things that matter most to older people may be ignored, to the detriment of their wellbeing. An example of this is when safeguarding focuses on the concerns of professionals rather than people with dementia which can lead to what has been termed 'silent harms' (Clarke et al 2011) associated with over-protection and risk aversion. This tendency towards low expectations can significantly undermine older people's sense of identity, agency and significance (Author $Y$ and author 1 2016), failing to support balanced reciprocal relationships and associated mental well-being (Fyrand 2010). Yet the approach remains prevalent reflected in the literature on research, learning and improvement where, with notable exceptions, the involvement of older people with high support needs is rare (Tanner 2012, Blood 2013).

The second challenge is overcoming the low status and expectations of frontline care practitioners, which is reflected in their pay, working conditions and education (Innes et al 2007). Media coverage of social-care services such as care homes is often negative, dwelling on the worst examples of poor practice (Welsh Government 2015), although initiatives such as My Home Life (Owen and Meyer 2012) challenge this by highlighting good practice. As a result, the emphasis is often on nonquestioning compliance with standardised procedures and pre-determined learning outcomes, rather than practitioners crafting diverse types of knowledge and wise, contextualised practice (Schwartz and Sharpe 2011) for the benefit of the people they support.

As a result of these two challenges, both older people and frontline care practitioners have traditionally rarely been invited to co-create knowledge and co-produce policy and services. In organisational cultures based on compliance rather than creativity, they often end up as 'policy victims' rather than 'policy entrepreneurs'(Glasby 2012), which can stifle innovation and undermine well-being (Wilson et al 2018).

What is required is the development of a common language (Edwards 2012) facilitated through meaningful dialogue across all stakeholders (Bate and Robert 2007, Author 5 et al 2014) if we are to see diverse types of knowledge, including research used in the co-production of policy and practice. Dialogical practice based on stories as stimuli, offers an avenue towards redressing some of the unintended harms of policy and practice focused on process and technical solutions rather than relationships and contextualised, responsive practice (Trevithick 2014).

The benefits of opening-up reflective spaces to enable transformative dialogue about care and support for older people which is more attuned to their concerns, has already been demonstrated (Ward and Barnes 2016), as has the understanding that care is a collective responsibility (Tronto 2010); "A relational ontology in which interdependency is understood as a defining feature of human life" (Ward and Barnes 2016, p 907).

Here, we explore the use of story in bridging the gap in knowledge exchange. Recognising that human beings are story-telling animals who make sense of the world through narrative understanding (Lyle 2000, Davies and Powell 2010, Gottschall 2013), we explore the role of story as a powerful tool in conveying complex and multi-dimensional ideas as well as building caring relationships and enabling connections to be made between different types of knowledge and experience. This has the potential to lead to meaningful policy and practice developments that are enriched, not simply directed by evidence. 


\section{Study design}

\section{Background}

This paper discusses a two-year participatory action research project (Author 1 et al 2015) where researchers worked alongside older people and carers; diverse social care and health practitioners (including social workers; social care workers; occupational therapists and nurses)and service managers, in 6 sites across Wales and Scotland. Funded by $X$, they sought to work together to address seven 'Challenges' derived from extensive research on what contributes to 'A Better Life' for older people with high-support needs (Blood et al 2013). The 'Challenges' were:

- Promote a more positive image of old age - no them and us;

- See the person behind the label or diagnosis;

- Recognise that helpful support is founded in and reflects meaningful and rewarding relationships;

- Enable the opportunity for older people to give as well as receive;

- Share responsibility with older people (e.g. in making decisions and promoting collective well-being);

- Strengthen the individual and collective voice of older people;

- Recognise that 'little things' as well as significant innovations can make a big difference.

The fact that the findings of this five-year programme of research were framed as 'Challenges' is significant in that they were intended to promote discussion and dialogue, rather than standardised compliance with recommendations. Our project was funded specifically to explore this approach, which is consistent with social pedagogy in not seeing intended learners as 'empty vessels' to be filled: "Now that use of expert knowledge is different from having the expert telling people what to do, and I think that's where I draw the line. I have no problem with using information that experts have as long as they don't say this is what you should do." (Horton and Freire 1990 p130).

The 'Challenges' were also adopted as principles underpinning the approach taken in progressing our project in terms of form and content. Stories were sought which could help to illustrate and address the 'Challenges', and dialogue was encouraged, to enable the voices of older people, carers and practitioners to be heard.

\section{Methods}

Ethical approval for the research was given by author 1's university. Respecting the citizenship of people with dementia (Bartlett and O'Connor 2007), we assumed their capacity to consent and participate, but this was always on their terms. The project ran over two and a half years based on an action learning model developed by the Scottish Community Development Centre called the LEAP framework (Barr and Daily 2007). This was selected because of its inclusive and accessible approach grounded in community development, which we saw as transferrable to knowledge democracy (Powell and Feldman 2019) and participatory organisational change. This framework followed the action learning cycle of 'analyse, plan, do and review'. Here we sketch out core activities, detailed elsewhere (Author 1 et al 2015) of our 3-phase approach. Project facilitators sought from the outset to create and maintain a sense of involvement and 'safe' participation for all. The exchange model of assessment underpinned the approach (Figure 1) 


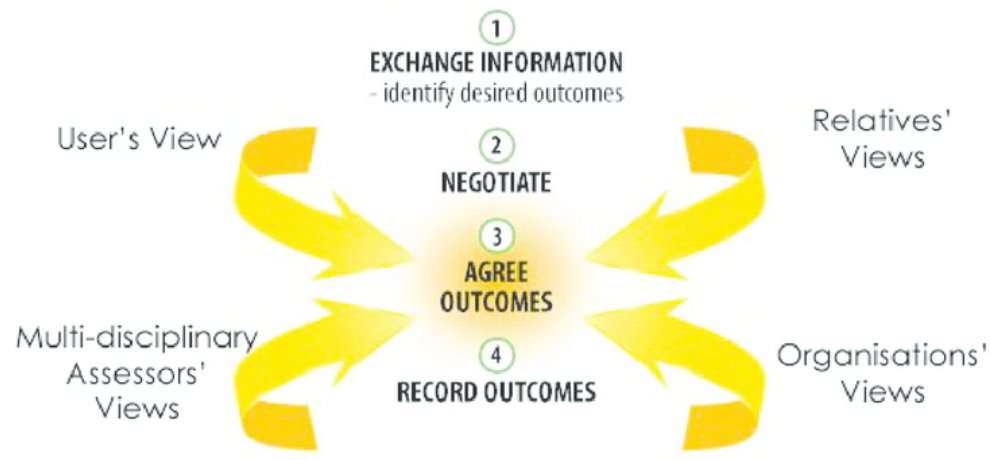

Figure 1: Exchange model (adapted by Author 1 and X 2016, from original by Smale et al 1993)

Phase 1

Phase 1 launched with an introductory event involving 2 or 3 practitioner/manager representatives from each project site to introduce the JRF programme $A$ Better Life, the 'Challenges' and the project design. We then held audio-recorded focus groups in each of the 6 sites, involving 8 to 10 local older people and carers, where the 'Challenges' were shared as both statements and associated stories/vignettes, many based on real life examples, anonymised and sometimes blending more than one example to provide illustrations of each challenge. This approach was based on the understanding that effective learning is best grounded in and built on the narratives and priorities of the people involved, whilst also introducing respectful challenge and critical reflection (Horton and Freire 1990, Mercer and Littleton 2007). Participants were asked whether they had any similar or contrasting narratives to include as evidence, which were recorded and subsequently transcribed. In all focus groups, participants responded to stimulus stories with their own examples. For example, in a group of carers of people with dementia in Scotland, one woman told a story about how her dad, who had been in the navy and had always been very well organised and tidy, had taken on the role in the household of cleaning all waste materials for recycling. She noted that the material recycled was probably the cleanest received by the recycling plant and her dad was at his calmest when undertaking this role. This woman connected her dad's need to continue to contribute to 'seeing the person behind the label' and to 'being able to give as well as receive' and this first story was followed by many others told by carers in the group.

The focus groups were followed by project planning events in the 6 sites, each involving 10-15 people (a mix of diverse practitioners; managers; researchers; older people and carers). Participants further explored the 'Challenges' alongside the additional stories gathered from local focus groups. Participants in turn contributed their own experiences of the 'Challenges', generated ideas for service and workforce development, prioritised their ideas, and selected one topic per site for learning and development in Phase 2 The topics were:

- Relationship-centred practice - understanding it and putting it into practice

- Positive and rights-based approaches to risk management with people with dementia

- Developing meaningful activities in care homes and day services

- Supporting interdependent caring relationships through the development of meaningful short breaks

- Addressing loneliness and making an integrated resource centre a part of the community not apart from the community 
- Developing personal outcome-focused recording for assessment, planning and review of support for older people

Forty-two semi-structured telephone interviews were undertaken with participants from all 6 sites at the end of phase 1, providing further opportunity to explore interaction between evidence, stories, dialogue, learning and progress with the 'Challenges'. Thus, cycles of stories were used to connect with people's knowledge and experiences which in turn generated new related but distinct stories from different perspectives.

To further facilitate the inclusion of all, participants were introduced to validated and practical techniques regarding dialogue-based learning (Mercer and Littleton 2007) and democratic decision making (Escobar 2011). One such technique was Community of Enquiry (Golding 2015), that builds relationships, knowledge sharing and collective learning through generating and exploring a conceptual question in response to an evidence stimulus.

Phase 2

Monthly half-day action-learning events in each of the 6 sites continued over a period of 6 months, involving 5-15 members, again reflecting diverse stakeholder membership, i.e. older people and carers; practitioners; managers and researchers. The project facilitators introduced appropriate research knowledge in response to the interests and learning needs of participants. For example, in the site exploring relationship-centred practice, participants requested evidence around well-being and the importance of relationships. In response to this, they were introduced to research on social ostracism (Williams and Nida 2011) in the form of a short film based on the research findings and personal experience of a social psychology researcher. The story format clearly engaged both the minds and hearts of participants, as a result of its intellectual and emotional content.

Representatives from each site shared learning at a networking event in $Y$ at the end of Phase 2.

In February 2015, a second series of facilitated focus groups in each of the 6 sites, involving 4-10 Phase-1 participants, discussed progress and suggestions for follow-up work. They were also asked to complete two profiling tools. Firstly, the Senses Framework (Nolan et al 2006) helped to gauge whether and how the project had enhanced participants' sense of security; continuity; belonging; purpose; achievement and significance. Secondly a model for evaluating participatory research (Hanson et al 2006) identified whether involvement had resulted in participants feeling valued and included and whether their collective ideas had borne fruit in practice. Thirty-eight semi-structured telephone interviews were undertaken with participants at the end of Phase 2 with a focus on evidence usage.

Phase 3

With additional funding from $X$, author 1 , as Principal Investigator, facilitated follow-up learning and development activities between May 2015 and June 2016, seeking opportunities for collaborative approaches to policy and practice development. This work included a range of learning and development initiatives, including a care homes learning and development resource based on capturing and sharing 'magic moments' - micro-narratives about what matters most to care home residents, which resonated with the 'Challenges': Weblink 1 
Findings

Focus group and interview data from Phases 1 and 2 were subject to a Framework Analysis (Ritchie and Spencer 1994) highlighting five key elements (outlined below) that enabled progress towards achieving the project sites' aims. The findings were published in a JRF Project report and 4-page Summary (Author 1 et al 2015). Development work, including Phase 3 was advanced more quickly in the project sites where all five elements were well supported and addressed. The five elements were as follows.

\section{Element 1: Valuing and using a range of evidence}

Consistent with the participant-led approach, the facilitators supported the use not only of research knowledge but also practitioners' tacit knowledge, older people's and carers' lived experience and managers' organisational knowledge (including policy direction). The approach essentially blended the exchange model in a learning context with use of diverse stories, giving all participants a voice (Figure 1). A notable example of this was the development of an 'evidence compared' table in one project site (Table 1), where the focus was on addressing the 'Challenge' - 'All good support is founded in and reflects meaningful and rewarding relationships'.

\begin{tabular}{|c|c|c|c|}
\hline \multicolumn{4}{|c|}{ Key 'A Better Life' Challenge: We must ensure that all support is founded in and reflects, meaningful and rewarding relationships } \\
\hline $\begin{array}{l}\text { Evidence from older people \& } \\
\text { carers }\end{array}$ & Evidence from frontline staff & $\begin{array}{l}\text { Organisational evidence - } \\
\text { current policy }\end{array}$ & Research evidence \\
\hline $\begin{array}{l}\text { 'One young girl (a homecare } \\
\text { assistant) became great friends } \\
\text { with mum - they just hit it off. } \\
\text { My mum loves this young girl } \\
\text { to death and she loves my } \\
\text { mum - it was just a natural } \\
\text { blossoming } \\
\text { friendship through their } \\
\text { professional relationship' }\end{array}$ & $\begin{array}{l}\text { 'I do think it is nice to be able } \\
\text { to share... clients will ask us, } \\
\text { what have you done over the } \\
\text { weekend and personally, I } \\
\text { don't see anything wrong... I } \\
\text { think you have got some } \\
\text { boundaries that have gone a } \\
\text { bit OTT and it is so sad that if } \\
\text { someone was to ask me "Are } \\
\text { you married? Have you got any } \\
\text { children?" and for me to say “I } \\
\text { am sorry, I cannot discuss this } \\
\text { with you"' }\end{array}$ & $\begin{array}{l}\text { 3.1 Becoming the friend of a } \\
\text { person who uses our services } \\
\text { is an inappropriate relationship } \\
\text { that focuses on the needs of } \\
\text { both people. A professional } \\
\text { relationship should focus } \\
\text { solely on the needs of the } \\
\text { person who uses our service. } \\
\text { Becoming a friend of that } \\
\text { person is inappropriate }\end{array}$ & $\begin{array}{l}\text { We are social beings and being } \\
\text { socially ostracised in anyway } \\
\text { results in either despair or rage } \\
\text { - people need to feel that they } \\
\text { belong and matter. This is } \\
\text { expressed most powerfully } \\
\text { through high quality reciprocal } \\
\text { and inclusive relationships } \\
\text { (Williams and Nida 2011) } \\
\text { Mental well-being is linked to } \\
\text { having balanced reciprocal } \\
\text { relationships where the person } \\
\text { is not 'over-benefitted' or } \\
\text { 'under-benefitted'. This } \\
\text { requires a culture of 'give and } \\
\text { take' (Fyrand 2010) }\end{array}$ \\
\hline
\end{tabular}

\section{Table1: Extract from 'Evidence Compared' table used to stimulate dialogue}

This table revealed clearly that organisational knowledge (as set out in policy) was at odds with the evidence from research, older people's experience and practitioner knowledge. It became a very effective catalyst for dialogue, and contributed to a change in organisational policy regarding professional boundaries, which is discussed in more detail later.

\section{Element 2: Creating an enriched environment of care and learning}

The role of bottom-up experimentation and creativity can be threatening, particularly in organisations with a top-down and risk-averse approach to performance (Patterson et al 2011). Organisations seeking to nurture innovative improvements must create an enriched environment of care and learning (Nolan et al 2006) before expecting anyone to proactively and creatively engage with evidence and innovate (Hill et al 2014). At the start of the project, visible senior management buy-in was therefore secured in each project site, in the form of letters of support. Senior managers not only gave permission for experimentation, but also became personally involved in the research through being participants in focus groups and Communities of Enquiry. For example, in one Community of Enquiry in the site referred to under Element 1, an extra-care service tenant began to 
cry when she shared her story about losing all her family and friends, and how she now felt when staff said to her that they were not allowed to be her 'friend' because of the organisation's professional boundaries policy. In response, a senior manager in the group, made a commitment to support a policy change, that underpinned a more relational approach to practice and was extended across the organisation.

Creating an enriched environment of care and learning also required purposeful recognition of the interdependent well-being of older people; carers and practitioners, all of whom need to experience a sense of security; continuity; belonging; purpose; achievement and significance (Nolan et al 2006). The importance of feeling valued was identified throughout as critical to enabling all participants to explore and use evidence. This was illustrated by an older person with dementia in one of the first focus groups:

"Listen, I am nobody, only my name and what I have done... I would like to be involved and I would like to help you all. I can give you advice, but I think it is better not to involve me in this... because of my age and my failure in memory, whatever... because of my uselessness" [Georgie]

This man, whose story was previously unknown by services, became a key contributor to the project, subsequently producing an anti-bullying book for children based upon his life story (Davies and Beer 2015 - Figure 2). This book and the story of how it came to be written, became a key catalyst and learning stimulus in demonstrating and addressing many of the 'Challenges', as discussed later.

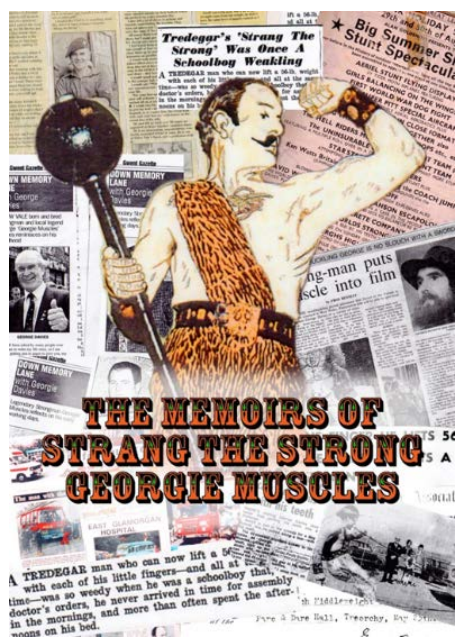

Figure 2: The power of story in presenting the $A$ Better Life Challenges

Participants across all 6 sites often talked about their lack of agency. A common statement by participants (older people; carers and practitioners) was "We're not allowed..." One older person described how she was not allowed to pour a cup of tea for the person next to her, because of health and safety rules. Some participants working in frontline social care services recounted how, prior to the research project, they often felt undervalued and disempowered, describing themselves as being "unqualified" or "only a care assistant". They talked about being "sent on training courses" or "seen as being negative if we don't agree with the managers", rather than being encouraged to develop their own ideas and interests. With exceptions, they stated that prior to the research project, they did not feel understood or supported by senior managers and other professionals.

Our learning and development sessions were therefore often focused on building relationships between the different stakeholder groups and achieving the necessary changes in organisational attitudes that could permit an enabling environment to emerge. The collaborative, dialogic and 
caring approach to the research project gave practitioners; older people and carers renewed confidence and motivation to, as one participant stated, "make the world a better place".

\section{Element 3: Presenting evidence in meaningful formats}

We identified that in order to draw research knowledge into the mix of knowledge exchange, it needed first to be formatted in narrative ways that engage both the head and the heart, rather than presented as a list of bullet-point recommendations.

In the initial telephone interviews at the end of Phase 1, participants across all project sites struggled to recall the actual 'Challenges'. However, they readily recalled both the fictional and factual narratives from the focus groups and other events that conveyed those very same research-based principles. They also described how the narratives challenged their thinking and practice, especially when there was a poignant emotional component.

One of the most powerful factual narratives that encapsulated most of the 'Challenges' was about Georgie (quoted above), who had talked about his "uselessness". Through a process of assisted lifestory work, he went on to talk about his early life as a professional strong man who had raised lots of money for charity. It transpired that he had become a strong man because he had been bullied at school, and he wanted to share his story with children in a similar situation. He had a carrier-bag of photos that he wanted to put together in a book, which became his Phase 2 project work. With help from an artist, he went on to write a simple anti-bullying book for children, based upon his life, later used with primary school pupils (Figure 2). In addition to creating a sense of achievement and significance for the man concerned, this activity provided a powerful exemplary narrative that was used as a catalyst for dialogue-based learning and development during Phase 3 of the project. The book was published and made available to a wider audience via the People's Collection website hosted by the National Library of Wales: (Davies and Beer 2015).

The power and effectiveness of research presented as narrative was also demonstrated in Phase 3 development work. For example, through a collaborative approach, practitioners in care homes were able to share practice evidence which resonates with and brought to life the 'Challenges'. Working with their managers and dialogue-learning experts in the University of Cambridge, they developed a storytelling learning resource called 'Magic Moments' (see Table 2 for an example story)

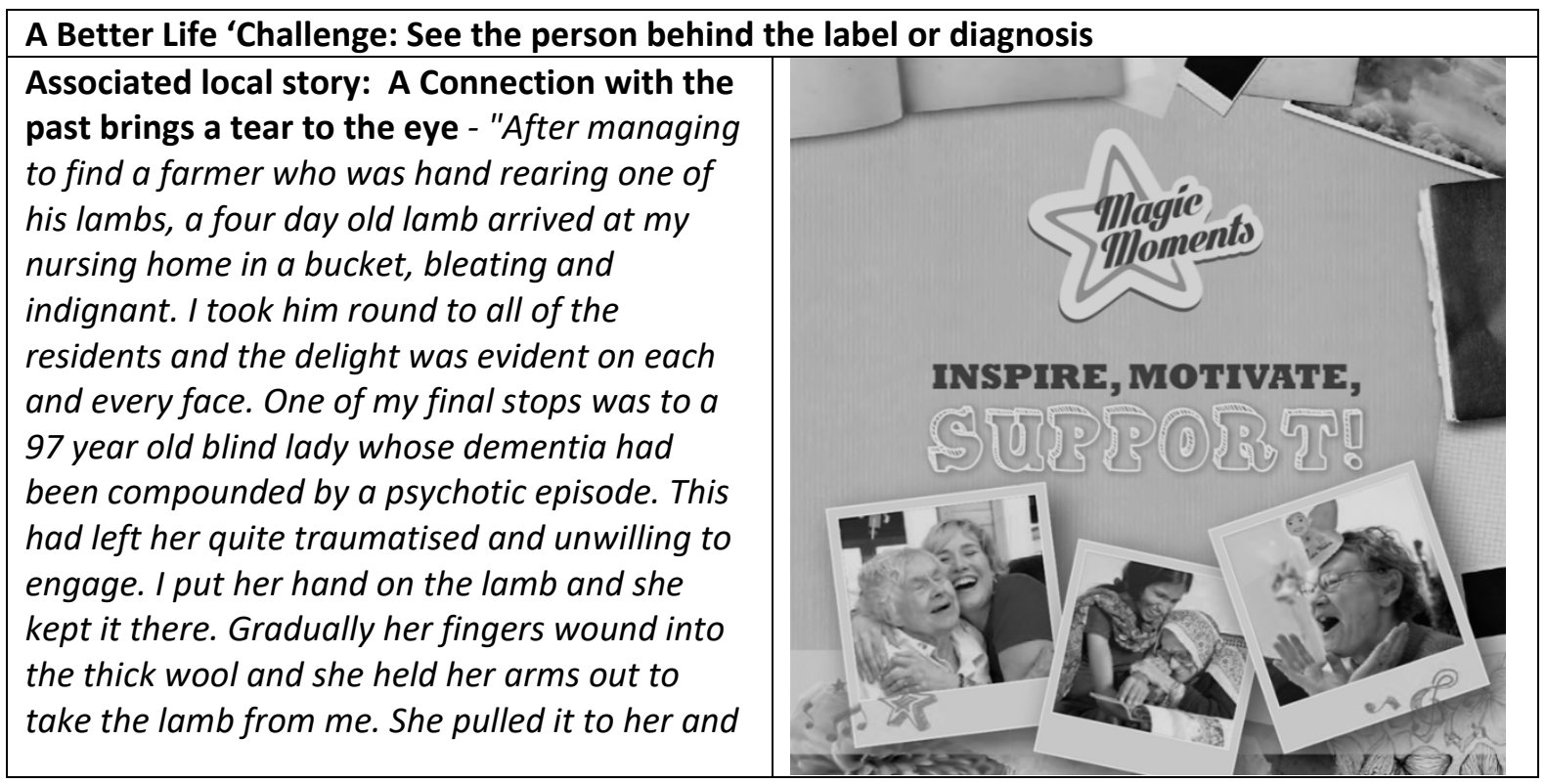


buried her face into it breathing in the warm, oily scent. After a minute a tear fell down her cheek and she lifted her head up and said, "I was in the land army, I cycled six miles every day to the farm where I worked and I was in charge of the lambs. Their fleeces would help defrost my fingers. I'd forgotten..."

Table 2: A Better Life 'Challenge' as expressed through local stories in care homes (for book with more stories see http://www.careforumwales.co.uk/uploads/MagicMoments PDF.pdf )

Element 4: Effectively talking and thinking together about diverse types of evidence, which may conflict

Practitioners participant from all 6 sites related frustrating experiences of meetings failing to support meaningful conversations that allowed genuine scrutiny of the practicability of using evidence in policy and practice:

"We have lots of meetings, but nobody ever meets in the real sense of the word" (social worker)

"We used to talk with our managers, but now we have to sit through policy briefings" (frontline social care worker)

"We are either told off, or told what to do" (care home manager)

We have already referred to our use of Community of Enquiry as an approach which encourages expression of different opinions, working towards consensus through the collective and respectful probing of the assumptions behind, and implications of, the diverse opinions and sources of evidence that emerge. Community of Enquiry is underpinned by a set of ground rules, which ensure that everyone's voice is heard and respected (Lipman 2003, Christie et al 2007).

At the site working on relationship-centred practice, a Community of Enquiry involving older people, carers, diverse practitioners, researchers and managers generated the question 'Can staff be friends with service users and their families?' The initial stimulus for this enquiry, was a children's story book called Wilfrid Gordon Mcdonald Partridge (Fox and Vivas 1987), which tells the story of a young child who becomes friends with a care home resident living with dementia. Through this Community of Enquiry and other narrative and dialogue-based discussions throughout the organisation, both practice and policy began to change. The organisation developed a new Sharing Lives and Professional Boundaries Policy, incorporating all the evidence sources and allowing clientpractitioner relationships to blossom.

Element 5: Recognising and addressing structural obstacles

Participants identified systemic problems which needed to be addressed such as excessive, poorly designed paperwork (Warmington et al 2014) and resource management systems that reduced time to spend with people, or a culture of risk aversion, often in the name of health and safety but probably linked more to fear of litigation. The term 'undercover kindness' was coined for many of the practice narratives; examples of practitioners bending the rules to do the right thing for someone, but not telling anyone for fear of repercussions. This is consistent with critiques of New Public Management in general (Tomo 2018) and the use of targets and incentives that can undermine wise and virtuous practice (Schwartz and Sharpe 2011). Another obstacle was narrow understanding of concepts such as independence (e.g. based solely upon physical capabilities and 
the need to save money by reducing social care services) or respite(e.g. based solely on burden and the need for separation).

\section{Lessons from the approach to project planning}

Whilst the project commenced with the development of a LEAP logic model project plan (Barr and Dailly 2008), many positive outcomes were unplanned and unpredictable. They came about through a responsive, dialogic and emergent approach, which is consistent with co-produced theories of change, which need to be fluid (Ghate 2018). Whilst there was merit in discussing the intended purpose and outcomes at an early stage of the project, participants resisted the initial request to complete their own on-line logic model plans and talked about "being project-planned to death". They wanted freedom to be creative and "go with the flow", which is consistent with a complexity approach to project management and evaluation (Auspos and Cabaj 2014, Mowles 2014).

Sustainability of the approach developed and move towards evidence-enriched practice

The five key elements (Table 3) identified became the foundation for the Developing EvidenceEnriched Practice (DEEP) approach, which became a programme of work under the Wales School for Social Care Research. Since the project, the DEEP approach has been well received and applied across a range of social care organisations. It has also been embedded in the Good Work: Dementia Learning and Development Framework for Wales (Care Council for Wales and NHS Wales 2016) and the Social Care Research and Development Strategy for Wales 2018-23 (Social Care Wales and Health and Care Research Wales 2018)

\begin{tabular}{|l|l|}
\hline Element & Summary \\
\hline $\begin{array}{l}\text { Valuing and using a range of } \\
\text { evidence }\end{array}$ & $\begin{array}{l}\text { Taking a democratic approach to knowledge exchange, which } \\
\text { values and uses diverse types of evidence, including research } \\
\text { knowledge, practitioner knowledge, lived experience of service } \\
\text { users and carers and organisational knowledge }\end{array}$ \\
\hline $\begin{array}{l}\text { Creating an enriched } \\
\text { environment of care and } \\
\text { learning }\end{array}$ & $\begin{array}{l}\text { Securing senior management support and facilitating the } \\
\text { creation of inclusive and safe spaces, within which participants } \\
\text { feel valued and able to share their thoughts and feelings in } \\
\text { relation to learning and development }\end{array}$ \\
\hline $\begin{array}{l}\text { Presenting evidence in } \\
\text { meaningful formats }\end{array}$ & $\begin{array}{l}\text { Presenting all types of evidence in formats that are engaging } \\
\text { and stimulate both an intellectual and emotional response. For } \\
\text { example; stories, poems and provocative statements }\end{array}$ \\
\hline $\begin{array}{l}\text { Effectively talking and thinking } \\
\text { together about diverse types of } \\
\text { evidence, which may conflict }\end{array}$ & $\begin{array}{l}\text { Using validated dialogue learning techniques and skilled } \\
\text { facilitation to support the inclusive and equitable exploration } \\
\text { of diverse types of evidence within the context of practice }\end{array}$ \\
\hline $\begin{array}{l}\text { Recognising and addressing } \\
\text { structural obstacles }\end{array}$ & $\begin{array}{l}\text { Identifying and addressing systemic issues that undermine or } \\
\text { obstruct the use of evidence in practice. For example; } \\
\text { bureaucratic processes and organisational culture }\end{array}$ \\
\hline
\end{tabular}

Table 3: The fine elements of the Developing Evidence-Enriched Practice (DEEP) approach

The term evidence-enriched was chosen because it implies adding value to practice rather than 'telling it what to do' (evidence-based) or just 'chipping in' (evidence-informed). The term is also consistent with the established concept of enriched environments of care and learning (Nolan et al 2016), which likewise prioritises relationships which nurture the interdependent well-being of all stakeholders. 


\section{Discussion and conclusions}

Storytelling is a very human form of communication. Most leaders understand that stories can initiate action and communicate values (Denning 2006). Narrative repetition or the retelling of stories has been studied for its effects on maintaining consistency and reaffirming beliefs (Dailey and Browning 2014). Whatever the aim of story-telling and retelling, it is found that resistance can follow if people feel they are being coerced. Resistance can take the form of open rejection or subtle forms of cynicism and irony (Dailey and Browning 2014). However, a storytelling culture is required for learning and change to be widely adopted and sustained (Davidson 2017). The key is a respectful approach.

While much has been written about the power of story in promoting change in organisations (Barker and Gower 2010); about the power of story in communicating research findings (Keen and Todres 2007) and about the role of dialogue in organisations (Hill et al 2014), our research explored a story based dialogical approach to promoting evidence-enriched policy and practice across multiple organisations in health and social care. In so doing, it recognised that dialogue is more than the process of talking and exchanging knowledge; it is about "Responding to others as if they really matter and building dispositions to seek out, value and learn from the differences between us" (Rupert Higham, personal correspondence). It is a deeply caring activity that values everyone who is involved, whilst recognising and encouraging the expression of multiple and diverse perspectives (Higham et al 2015). Starting out with 'Challenges' rather than recommendations, we prioritised participants' knowledge and reality.

A key element in the success of the project was the quality of facilitation by the researchers, who were at the same time research knowledge brokers (Lightowler and Knight 2013). The approach required a caring and inclusive attitude, diplomacy and the ability to help diverse individuals in homogeneous groups feel welcome. The aim was to create spaces in which participants felt valued and safe to share and explore what they really thought and why, whilst also being able to collectively question the assumptions and implications behind what was being shared. While one of the tasks of the facilitators was to bring research knowledge to the project, there was no assumption that this was superior to the other forms of knowledge brought by other participants.

Whilst some authors suggest that those who work in social care mistrust research (Orme and Powell 2007, Petersen and Olsson 2015), our research found that participants took an interest in and were keen to engage with research findings when they related to their reality and matters of importance to them. The centre-staging of participants' main concerns through dialogue and narrative helped shape their exploration not just of research knowledge but also the views and experiences of older people and carers, the expertise of practitioners and organisational knowledge including internal policies.

A dialogical approach to storytelling helps to build a common language and vision (Edwards, 2012). When all participants in a group are invited to contribute and exchange stories, there is potential to build a set of shared values and principles, in language which makes sense to all participants (Miller, 2018, Riebe et al 2016). Stories in this context are not just about the celebration of victory narratives but must also bring to the surface tensions, dilemmas and barriers to achieving a good outcome (Escobar 2011. Littleton and Mercer 2013). In the context of health and social care services such tensions and dilemmas include navigation of risks and outdated and sometimes rigidly imposed rules and processes (often associated with bureaucracy), which are viewed as impeding the pursuit of common goals. 
Stories can help to soften cultures of compliance and open up ways of thinking creatively and collectively about pursuit of common goals. It is not however, just the singular story that creates this space, but rather a culture of storytelling, dialogue and exchange built around multiple voices and diverse stories. Thus stories become the building blocks forming the foundation or culture that binds together an organisation and all who come into contact with it. If research knowledge can be woven into the stories told within an organisation and blended with the knowledge, experience and wisdom of the actors who engage with it then the possibilities for an enriched environment of care and learning open up to all involved (Nolan et al 2006). The quality of facilitation is clearly critical here, in ensuring the culture of mutual respect is maintained and that all perspectives can be heard.

Perhaps one of the most significant uses of story exchange within organisations is as a tool to facilitate 'unlearning' (Thomas and Seely Brown 2011). Organisational culture, or the 'way we do things around here' is notoriously difficult to shift because of that tacit, taken for granted element to our knowledge (Littleton and Mercer 2013). Because we don't always know what we know, unlearning can be more difficult to achieve than learning. Where individuals have adopted practices without conscious awareness of absorbing them, they are unlikely to be amenable to rational argument. An emotional or intuitive connection is required to break through the tacit understanding and stories can help with this (Sole and Wilson 2002). This is now increasingly recognised as dependent on organisational culture and embedded systemic processes which impact on frontline behaviours and practices (Rycroft Malone 2004, Nutley et al 2007, Patterson et al 2011, Lightowler et al 2018).

In our project, meaningful and respectful conversations between participants provided the vehicle for considering and tackling systemic barriers towards success. These included well-meaning national and organisational rules and regulations that did not always fit well with contextual decision-making and what participants felt was most important in promoting well-being. It also required an approach to project planning that was emergent and responsive (McMillan 2008, Auspos and Cabaj 2014). While agreeing intended outcomes helped engage diverse partners in defining each project's purpose, many of the most valued results could not have been predicted.

Permission to explore and experiment, as well as to engage in dialogue is essential. Senior managers have to support participants to be creative and able to experiment with ideas, through showing appreciation and acknowledging and celebrating successes (even little ones) and through exploring the learning from less successful efforts too. Trusting relationships need to be developed between everyone involved, through opening dialogue in team meetings and supervision, including discussion of organisational values and sharing examples of good and challenging practice, so that people can be honest and feel safe.

If research knowledge is to fully impact on services, it must engage in effectively melding different sources of evidence within the context of practice (Flyvbjerg et al 2016). Deciding 'what counts as knowledge and whose knowledge counts' (Hodgson and Canvin 2005) often entails challenging inherent power structures (Alinsky 1971, Beresford 2018, Hall and Tandon 2019). Research knowledge can never be implemented or imposed. Rather, we found it has to be folded into discussions as it became relevant over time, and blended with other forms of evidence to develop 'mindlines' (Authors 2 and 32004,2011 and 2016), the collectively internalised, 'knowledge-inpractice-in-context' that informs day-to-day practice.

Whilst this made it difficult to isolate which part of the process resulted in change, practitioner participants generally reported positive personal impacts including satisfaction from their otherwise often undervalued work and, most importantly, improved quality of life of the older people and 
carers they work with. Perhaps the most significant ingredient in this approach to policy and practice development was the use of multiple forms of story, which engaged hearts and minds and challenged assumptions about the value of different voices and perspectives. In other words, the centrality of multiple stories enabled formal evidence to be blended through dialogue involving diverse perspectives, in a context of caring about what matters, to achieve the evidence enriched practice which otherwise often remains an elusive quest.

\section{References}

Alinsky, S. (1971) Rules for Radicals: A Pragmatic Primer for Realistic Radicals, New York, Vintage Books

Auspos., P. and Cabaj, M. (2014) Complexity and Community Change Managing Adaptively to Improve Effectiveness, Washington, The Aspen Institute

Ballatt, J. and Campling, P. (2011) Intelligent Kindness: Reforming the Culture of Healthcare, London, RCPsych Publications

Barker, R. and Gower, K. (2010) Strategic Application of Storytelling in Organizations: Toward Effective Communication in a Diverse World, Journal of Business Communication, 47(3), 295-312

Barr, A. and Dailly, J. (2007) LEAP Step-By-Step: An Introductory Guide to the LEAP Framework (2nd edition), London, Community Development Foundation

Bartlett, R. and O'Connor, R. (2007) 'From personhood to citizenship: Broadening the lens for dementia practice and research', Journal of Ageing Studies, 21(2), 107-118

Bate, P. and Robert. G. (2007) Bringing user experience to healthcare improvement: The concepts, methods and practices of experience-based design, Abingdon, Radcliffe

Beresford, P. (2018) 'Public participation in health and social care: Exploring the co-production of knowledge, Frontiers in Sociology, 3(41), 1-12

Blood, I. (2013) A Better Life: Valuing our later years, York, Joseph Rowntree Foundation

Booth T. and Ainscow M. (2016) Index for Inclusion; a guide to school development led by inclusive values, Index for Inclusion Network, Cambridge.

Bowers, H., Lockwood, S., Eley, A., Catley, A., Runnicles, Mordey, M., Barker, S., Thomas, N., Jones, C. and Dalziel, S. (2013) Widening choices for older people with high support needs, York, Joseph Rowntree Foundation

Cahn, E. (2000) No More Throw-away People: The Co-production Imperative (2nd edition), Washington, Essential Books

Care Council for Wales and NHS Wales (2016) Good Work: A Dementia Learning and Development Framework for Wales, Cardiff, Care Council for Wales. Available at: Weblink 3

Christie, D., Cassidy, C., Skinner, D., Coutts, N., Sinclair, C., Rimpilainen, S. and Wilson, A. (2007) Building Collaborative Communities of Enquiry in Educational Research, Educational Research and Evaluation, 13(3), 263-278

Clarke C., Wilkinson, H., Keady, J. and Gibb, C. (2011) Risk and Dementia Care, London, Jessica Kingsley. 
Cook A and Miller, E (2012) Talking Points: Personal Outcomes Approach. Practical Guide. Edinburgh, Joint Improvement Team

Dailey, S. and Browning, L. (2014) Retelling stories in organisations: Understanding the functions of narrative repetition, Academy of Management Review, 39, 22-43

Davidson, B. (2017) 'Storytelling and evidence-based policy: Lessons from the grey literature, Palgrave Communications, 3, 1-10

Davies, G .and Beer, C. (2015) The Memoirs of Strang the Strong. Georgie Muscles, Carmarthen, Parlour Press. Available at: Weblink 2

Davies, H., Nutley, S. and Smith, P. (2000) What works? Evidence-based practice in policy and public services, Bristol, Policy Press

Davies, H. and Powell, A. (2010) Helping social research make a difference. Exploration of a wider repertoire of approaches to communicating and influencing through research, St Andrews, Research Unity for Research Utilisation, St Andrews University

De Sousa Santos, B. (2007) 'Beyond Abyssal Thinking: From Global Lines to Ecologies of Knowledges', Review (Fernand Braudel Centre), 30(1), 45-89

Denning, S. (2006) Effective Storytelling: strategic business narrative techniques. Strategy and Leadership, 34, 42-48

Drumm, M. (2013) The role of personal storytelling in practice, Glasgow. IRISS

Edwards, A. (2012) 'The role of common knowledge in achieving collaboration across practices', Learning Culture and Social Interaction, 1(1), 22-32.

Escobar, O. (2011) Public Dialogue and Deliberation: A communication perspective for public engagement practitioners, Edinburgh: Edinburgh Beltane

Flyvbjerg, B. (2001) Making Social Science Matter: Why social enquiry fails and how it can succeed again, Cambridge, Cambridge University Press

Flyvbjerg, B., Landman, T. and Schram, S. (2016) Tension Points: Learning to Make Social Science Matter, Critical Policy Studies, Forthcoming. Available at SSRN: https://ssrn.com/abstract=2721321

Fox, M. and Vivas, J. (1987) Wilfrid Gordon Mcdonald Partridge, London, Puffin

Fyrand, L. (2010) 'Reciprocity: A Predictor of Mental Health and Continuity in Elderly People's Relationships? A Review', Current Gerontology and Geriatrics Research, 1-14

Gerrish, K., Guillaume, L., Kirshbaum, M., McDonnell, A., Tod, A. \& Nolan, M. (2011) 'Factors influencing the contribution of advanced practice nurses to promoting evidence-based practice among front-line nurses: findings from a cross-sectional survey', Journal of Advanced Nursing, 67(5), $1079-90$

Ghate, D. (2018) 'Developing theories of change for social programmes: Co-producing evidencesupported quality improvement', Palgrave Communications, 4, 1-12

Ghate, D. and Hood, R. (2019) 'Using evidence in social care' in Boaz, A., Davies, H., Fraser, A and Nutley, S. (eds.) What Works Now? Evidence-Informed Policy and Practice, Bristol, Policy Press, 89109 
Glasby, J. (2012) 'We have to stop meeting like this': what works in health and local government partnerships? Policy Paper 13, Health Services Management Centre and Institute of Local Government Studies, Birmingham University

Gotschall, J. (2013) The Storytelling Animal: How Stories Make Us Human, New York, Houghton Mifflin Harcourt

Green, H. (2016) How Change Happens, Oxford, Oxford University Press

Greenhalgh, T., Howick, J and Maskrey, N. (2014) 'Evidence based medicine: a movement in crisis?' BMJ 2014;348:g3725

Hall, B. and Tandon, R. (2017) 'Decolonization of knowledge, epistemicide, participatory research and higher education', Research for All, 1(1), 6-19

Hanson, E., Magnussen, L., Nolan, J. and Nolan, M. (2006) 'Developing a model of participatory research involving researchers, practitioners, older people and their family carers', Journal of Research in Nursing, 11(4) 325-342

Higham, R. J. E., Brindley, S., \& van de Pol, J. (2014). Shifting the primary focus: assessing the case for dialogic education in secondary classrooms, Language and Education, 28 (1), 86-99

Hill, L., Brandeau, G., Truelove, E. and Lineback, K. (2014) Collective Genius: The Art and Practice of Leading Innovation, Boston, Harvard Business School Publishing

Hodgson P,and Canvin K. (2005) Translating healthy policy into research practice: Involving service users in health and social care research, Abingdon, Routledge.

Horton, M. and Freire,P. (1990) We Make the Road by Walking: Conversations on Education and Social Change, Philadelphia, Temple University Press

Huxley, P. (2009) Social Care Research Priorities and Capacity in Wales: A Consultation Exercise, Centre for Social Work and Social Care Research, School of Human Sciences, Swansea University Innes, A., Macpherson,S. and McCabe, L. (2007) Promoting person-centred care at the front line: A review of the barriers and opportunities to the delivery of person-centred support/care by frontline workers, York, Joseph Rowntree Foundation

Keen, s. and Todres, L. (2007) Strategies for disseminating qualitative research findings: Three exemplars, Qualitative Social Research, 8, Art 17

Lavis J, Ross S, McLeod C, and Gildiner A. (2003) Measuring the Impact of Health Research, Journal of Health Services Research and Policy 8, 165-70.

Lightowler, C. and Knight, C. (2013) Sustaining knowledge exchange and research impact in the ocial sciences and humanities: investing in knowledge broker roles in UK universities' Evidence and Policy, 9(3), 317-334

Lightowler, C., Stocks-Rankin, C-R. and Wilkinson, H. (2018) How practitioner-led research could have greater impact: the importance of considering knowledge mobilisation holistically, Evidence in Policy, 14(4), 641-63

Lipman, M. (2003), Thinking in Education. (2nd ed.), Cambridge, Cambridge University Press

Littleton, K. and Mercer, N. (2013) Interthinking: Putting talk to work, London, Routledge 
Locock, I. and Boaz, A. (2019) 'Drawing straight lines along blurred boundaries: qualitative reseaech, patient and public involvement in medical research, co-production and co-design, Evidence and Policy, 15(3). 409-422

Lyle, S. (2000) 'Narrative understanding: Developing a theoretical context for understanding how children make meaning in classroom settings', Journal of Curriculum Studies, 32(1), 45-63.

McMillan, E. (2008) Complexity Management and the Dynamics of Change, Abingdon, Routledge

Mercer, N. \& Littleton, K. (2007) Dialogue and the Development of Children's Thinking: a sociocultural approach, London, Routledge.

Metz, A., Boaz, A. and Robert, G. (2019) 'Co-creative approaches to knowledge production: what next for bridging the research to practice gap?', Evidence and Policy, 15(3), 331-337

Miller, K. (2018) Practice research enabler: Enabling research in a social work practice context, Qualitative Social Work, 0(00) 1-16.

Mowles, C. (2014) 'Complex, but not quite complex enough: The turn to the complexity sciences in evaluation scholarship', Evaluation, 20(2), 160-175

Nolan, M., Brown, J., Davies, S., Nolan, J. and Keady, J. (2006) The Senses Framework: improving care for older people through a relationship-centred approach. Getting Research into Practice (GRiP) Report No 2. Project Report, Sheffield, University of Sheffield

Nutley, S., Walter, I. and Davies, H. (2007) Using Evidence - How Research Can Inform Public Services, Bristol, Policy Press

Orme, J. and Powell, J. (2007) 'Building Research Capacity in Social Work: Process and Issues', British Journal of Social Work, 38, 988-1008

Owen, T. and Meyer, J. (2012) My Home Life: Promoting quality of life in care homes, York, Joseph Rowntree Foundation

Patterson, M., Nolan, M., Rick, J., Brown., J. and Adams., R. (2011) From metrics to meaning: Culture change and quality of acute hospital care for older people, National Institute for Health Research Service Delivery and Organisation Programme.

Petersen, A. and Olsson, J (2015) Calling Evidence-Based Practice into Question: Acknowledging Phronetic Knowledge in Social Work, British Journal of Social Work, 45 (5), 1581-1597

Pratchett, T. (2013) Witches Abroad: (Discworld Novel 12), London, Corgi Books

Riebe, L. Girardi, A. and Whitsed, C. (2016) A Systematic Literature Review of Teamwork Pedagogy in Higher Education, Small Group Research, 47(6), 619-664

Ritchie, J. \& Spencer, L. (1994) 'Qualitative data analysis for applied policy research' in Bryman, A. and Burgess, R. (eds.) Analyzing Qualitative Data, Abingdon, Routledge, 73- 194.

Rowell, I. and Feldman, A. (2019) 'Knowledge democracy and action research', Educational Action Research, 27(1), 1-6

Rycroft-Malone, J. (2004) The PARiHS Framework - A Framework for guiding the implementation of evidence based practice, Journal of Nursing Care Quality, 19(4), 297-304 
Schwartz, B. and Sharpe, K. (2011) Practical Wisdom: The Right Way to do the Right Thing, New York, Riverhead Books

Smale, G. Tuson, G., Biehal, N. and Marsh, P. (1993) Empowerment, assessment, care management and the skilled worker, National Institute for Social Work Practice and Development Exchange, London: HMSO

Social Care Wales and Health and Care Research Wales (2018) Social care research and development strategy for Wales 2018-2023, available at: https://socialcare.wales/resources/social-care-researchand-development-strategy-for-wales-2018-2023---full-version

Sole, D. and Wilson, D. (2002) Storytelling in organisations: The power and traps of using stories to share knowledge in organisations, LILA, Harvard, Graduate School of Education, 1-12

Tanner, D (2012) 'Co-research with older people with dementia: experience and reflections'. Journal of Mental Health, 21(3), 296-306

Thomas, D. and Seeley Brown, J. (2011) A new culture of learning, cultivating the imagination for a world of constant change, Create Space

Tomo, A. (2018) Managerialism in the Public Sector: Perspectives and Prospects, Abingdon, Routledge

Tronto, J. (2010) 'Creating caring institutions: politics, plurality, and purpose', Ethics and Social Welfare, 4 (2), 158-171

Trevithick, P. (2014) Humanising Managerialism: Reclaiming Emotional Reasoning, Intuition, the Relationship, and Knowledge and Skills in Social Work, Journal of Social Work Practice, 28(3), 287311

Unwin, J. (2018) Kindness, emotions and human relationships: The blind spot in public policy, Danfermline, Carnegie UK Trust

Ward, E. and Barnes, M. (2016) Transforming practice with older people through an ethic of care British Journal of Social Work, 46(4), 906-922.

Warmington, J. Afridi, A. and Foreman, W. (2014) Is excessive paperwork in care homes undermining care for older people? York, Joseph Rowntree Foundation

Welsh Government (2015) The Flynn Report: In Search of Accountability. Available at: http://gov.wales/topics/health/publications/socialcare/reports/accountability/?lang=en

Wieringa, S., Engebretsen, E., Heggen, K. and Greenhalgh, T. (2018) 'Rethinking bias and truth in evidence-based health care', Journal of Evaluation in Clinical Practice, 24, 930-938

Williams, K. and Nida, S. (2011) Ostracism: Consequences and Coping, Current Directions in Psychological Science, 20(2):71-75

Wilson, R., Cornwell, C., Flanagan, E. and Halima Khan, H (2018) Good and Bad Help: How Purpose and Confidence Transform Lives. London, Nesta

Author 1 et al. (2009)

Author 1 et al (2015)

Authors 2 and 3 (2004) 
Revised blind V7 with tables

Authors 2 and 3 (2011)

Author 2 and 3 (2016)

Author 4 and Author X. (2016)

Author $Y$ and Author 1. (2016)

Author 5 et al (2014) 